\title{
THE EFFECT OF TREMATODE PARASITES ON THE GROWTH OF LITTORINA NERITOIDES (L.)
}

\author{
By Miriam Rothschild
}

(Text-figs. I-3)

\section{INTRODUCTION}

Observations and measurements made on the Gastropod mollusc Peringia ulvae (Pennant) $\mathrm{I} 777$ in the wild, suggested that infection with trematode larvae (parthenitae and cercariae) produced gigantism in the host. Experiments in the laboratory (A. \& M. Rothschild, 1939) showed that infected snails not only attained ultimately greater size, but also grew faster than uninfected specimens.

Unfortunately, it is difficult if not impossible to compare the growth-rate of an uninfected population with an infected one in nature, as very slight changes in environment (Rothschild, 1938) produce relatively enormous differences in size. Thus, for example, $P$. ulvae collected a few feet apart, on an apparently uniform and identical stretch of mud-flat give different growth curves. In the laboratory simple experiments have confirmed this. Young $P$. ulvae of under $2 \mathrm{~mm}$. in length, were kept for three weeks in water contaminated with gull faeces and subsequently changed to clean water. Their mean size at the end of six months was approximately half that of the controls which were kept in clean water throughout the experiment.

It was hoped to obtain a suitable standard of comparison for gauging the effect of trematodes on the growth of $P$. ulvae by discovering some common parasite which itself exerted no such effect, and to study its distribution throughout a population. A trematode using this snail as second intermediate host only, seemed the most obvious object of study. Unfortunately all the plentiful metacercariae found in $P$. ulvae, either use it as both first and second intermediate host, or else encyst on the outside of the shell. At first it was thought the latter might be utilized, as the chance of finding these cysts on the shell increased proportionately with the age of the snail. Experiments, however, showed that the cysts tend to be knocked off the shells without leaving traces of their presence, and it was therefore found impossible to utilize these species.

During Dr Averil Lysaght's study of Littorina neritoides (I94I, this volume, pp. 4I-67) it was discovered that this mollusc was commonly infected with a Ubiquita cercaria using the snail as first intermediate host, and a metacercaria using it as second intermediate host only. Dr Lysaght very kindly sent me her manuscript and invited me to publish a comment on this portion 
of her paper, thus giving me the opportunity of making the desired comparison. I would like to express my appreciation and gratitude for this exceedingly generous suggestion.

I would further like to thank Mr G. M. Spooner for his invaluable assistance, Miss Nora Sproston for her help in dissecting experimental gulls and chickens, and $\mathrm{Mr}$ W. Searle for collecting L. neritoides although exposed to shrapnel and gunfire.

\section{TREMATODE INFECTIONS OF LITTORINA NERITOIDES}

Dr Lysaght records four species of trematode larvae from this mollusc, but both Cercaria C, a species allied to Cercaria emasculans Pelseneer, and Cercaria D, a Notocotylid cercaria, occur too infrequently for inclusion in this study.

The commonest species met with, Metacercaria $\mathrm{A}$, using Littorina neritoides as second intermediate host only, is of uncertain systematic position, possibly allied to Cercaria tuberculata Fil. It forms a thick double-walled spherical cyst, slightly flattened dorsoventrally, and is found encapsuled in the liver and gonads of the host. Dr Lysaght states that it occurred in 3.3\% of the snails with a mean height of $2 \mathrm{~mm}$., and in $87 \%$ of those measuring $8.3 \mathrm{~mm}$. The number of cysts per snail increases in the large specimens, but their presence does not affect the seasonal development of the gonad. This metacercaria was found in snails infected with Cercaria B as well as in uninfected specimens. In fact, there appeared to be definitely more of these double combinations than should be expected by chance distribution alone.

The second common species, Cercaria B, is a typical Ubiquita cercaria using Littorina neritoides as first intermediate host only. Dr Lysaght found the percentage of infection very high for a marine mollusc, I4.65 for males and 29.7 for females. As already stated many of these infections also harboured Metacercaria A and there were a certain small number of true double infections when Cercaria B was found in conjunction with Cercaria C which also uses this snail as first intermediate host. The presence of these cercariae caused sterility in both sexes.

The distribution of both Metacercaria A and Cercaria B in the population of L. neritoides is shown in Fig. I, where the percentage of infection is plotted against size. Dr Lysaght draws attention to the fact that Cercaria B is less common in the smaller size groups than Metacercaria A. In addition to this it will be seen that the two curves are different. The one shown for Cercaria B is fundamentally the same as that demonstrated for Peringia ulvae infected with larval trematodes (see Fig. 2). Both display the comparatively low rate of infection in the small size groups and the rapid increase in infection rate in the large size groups, resulting in a steep curve upwards from the $6 \mathrm{~mm}$.

\footnotetext{
* Littorina neritoides was examined from the Breakwater, Plymouth, the same locality from which Dr Lysaght obtained her material. Metacercaria A was fed in large numbers to laboratory-reared gulls and chicks with negative results.
} 
group ( $5 \mathrm{~mm}$. for $P$. ulvae) to a maximum of 91 \% (100\% for $P$. ulvae) in the $8 \mathrm{~mm}$. group ( $7 \mathrm{~mm}$. for $P$. ulvae).

The curve for Metacercaria A, on the other hand, does not slope steeply upwards, but increases more or less uniformly to $87 \%$. In view of the observations made in the wild on $P$. ulvae and the evidence obtained in the laboratory with this species, it is suspected that the dissimilarity in the two curves is due to growth stimulation by Cercaria B. Moreover, assuming that

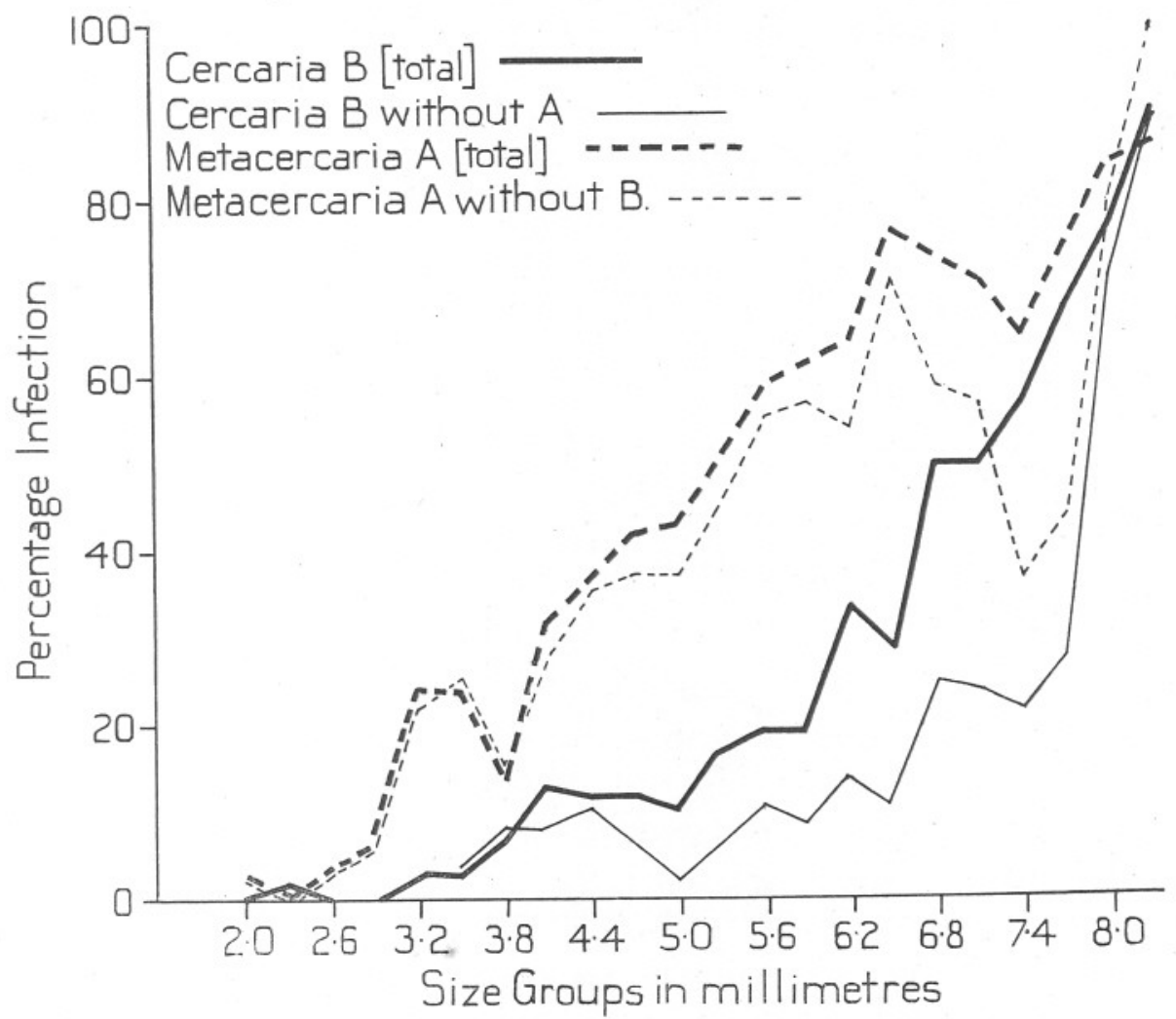

Fig. I. Percentage infection of population of L. neritoides, from data in Lysaght (194I, Fig. 9).

infection occurs at random and increases proportionately with the age of the snail, a far more probable computed growth curve is obtained if it is based on the curve shown for percentage infection of Metacercaria A (see below).

The depression in the upper portion of the curve for Metacercaria A is an anomaly which at present cannot be explained, and it is perhaps idle to speculate as to its possible cause. It does not, however, invalidate the arguments put forward above, as this deviation would, if anything, obscure the contrast obtained for the two curves. 
These figures were submitted to G. M. Spooner for criticism and he has very kindly analysed them and made the following comments.

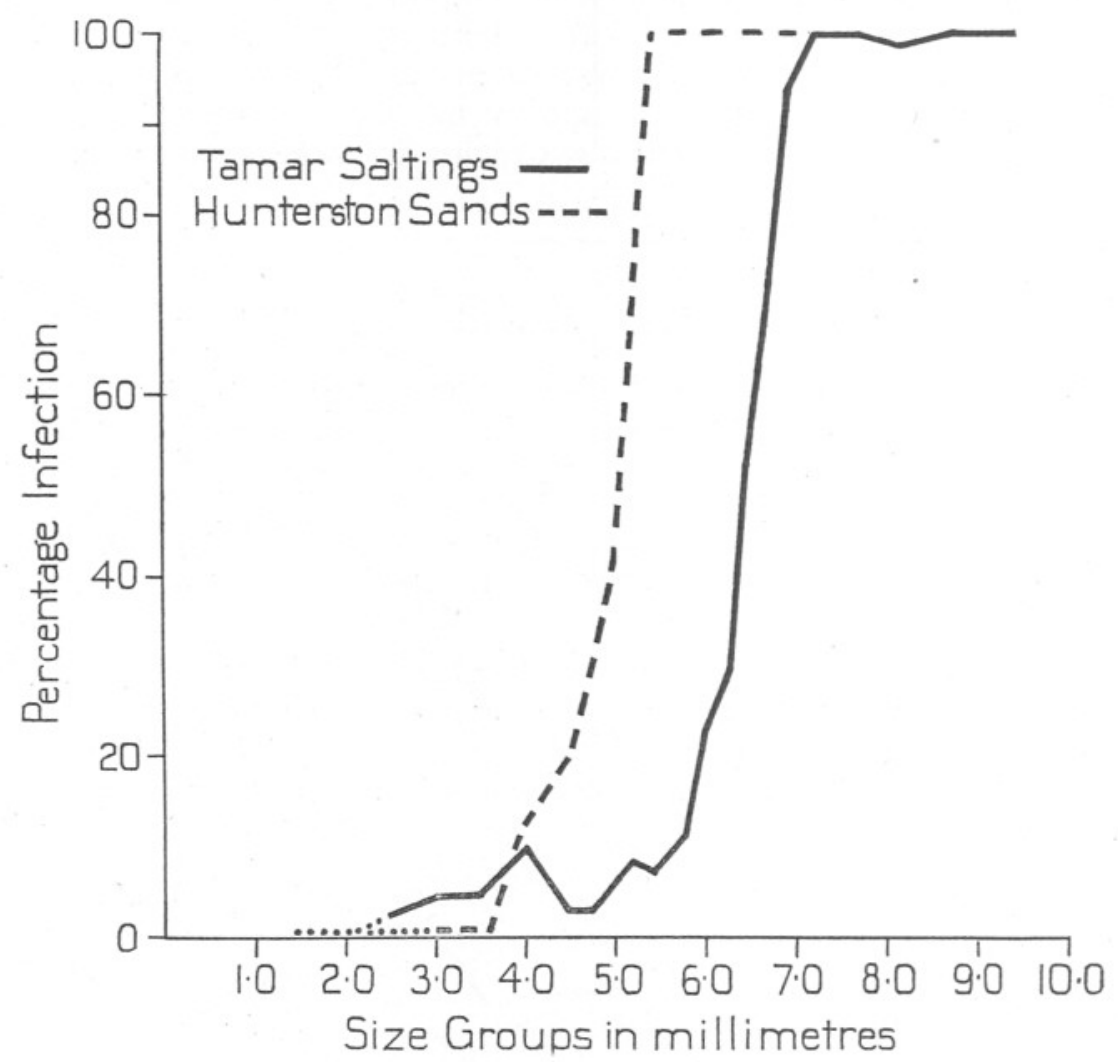

Fig. 2. Percentage infection of 2000 Peringia ulvae from Egypt Saltings, River Tamar, and Hunterston* Sands, Firth of Clyde.

\section{INTERPRETATION OF THE INFECTION CURVES}

The curves in Fig. I show how percentage infection increases with the size of the snail, or, if the diagram is inverted, how the percentage of the population remaining uninfected decreases with size. Size is a function of age, though the exact relation remains at present unknown. A decrease in freedom from infection as size increases is clearly to be expected, since the longer the snail lives the smaller is the probability that it has avoided contact with the trematode. But does this effect completely account for the shape assumed by both curves?

The method of approaching this question which gives the most instructive results appears to be the following. It is permissible to assume that the average

* Written erroneously as "Hunterdon" in Rothschild (1938). 
rate of infection of each trematode remains constant, or at least is independent of the size of the snail. In this event the percentage infection of a population plotted against time gives an ordinary exponential curve:

$$
i=\mathrm{IOO}\left(\mathrm{I}-\epsilon^{-a t}\right) \text {, }
$$

in which $i$ is the percentage infected, $t$ is the number of time units, and $a$ is a constant expressing the rate of infection. The formula for the percentage remaining uninfected $(u)$ is of simpler form. From the above,

$$
\frac{\mathrm{IOO}-i}{\mathrm{IOO}}=\epsilon^{-a t} \text {, hence } \frac{u}{\mathrm{IOO}}=\epsilon^{-a t} \text {. }
$$

This is a simple logarithmic relation:

$$
\log _{\epsilon} u-\log _{\epsilon} \mathrm{IOO}=-a t,
$$

hence

$$
\log u-2=-0.4343 a t \text {, or } 2-\log u=k t
$$

(in which $k=0.4343 a$ ). Thus the logarithm of the percentage infected falls off uniformly with time.

It follows at once that $\log u$ can be used to represent $t$, and so provide a time scale. If, therefore, size is plotted against $\log u$ (instead of, as in Fig. I, I $-u$ against size), the snail's growth curve is obtained. This curve, exemplified in Fig. 3, represents the only growth curve from which the particular percentage-infection curve obtained could have arisen. It is, of course, a limitation that the time units in which it is expressed are of unknown value: or rather, the time scale can only be expressed in fractions of a life span, which is of unknown duration. This defect, however, does not prevent a significant test being made-namely, whether the growth curves derived from the percentage-infection curves of the two trematodes are compatible.

The data for Metacercaria A may be considered first. The size intervals are plotted against $\log u$, in descending scale of the latter, and curve $A$ drawn through the points (Fig. 3). If $\log u$ is replaced by $2-\log u$, an ascending time scale is given ranging from $\circ$ to 0.88 , this range representing a nearly complete life span of the snail (actually it is the interval between the age at which infection is first possible, presumably during the first few months of life, and the age at which this particular population reaches an average size of $8.3 \mathrm{~mm}$.). If $t$ is time expressed in years, then the scale $2-\log u$ is in units of $k t, k$ being a constant depending on the annual rate of infection.

Curve $B$ is the curve similarly derived from the data of Cercaria B. Its time scale, $2-\log u$, is in units of $k_{1} t$. $k_{1}$ is not identical with $k$, since the infection rates of the two trematodes are independent, and indeed, as inspection of Fig. I suggests, evidently different, that for Cercaria B being the smaller. For the purpose of comparison the two curves should be superimposed so that the ratio between the units of the two time scales is that of $k_{1}$ to $k$ (i.e. of $a_{1}$ to $a$, or the ratio of the two infection rates). If no other factor affects the original percentage-infection curves than the most straightforward conditions which have been assumed, the two growth curves 
should then be coincident. In Fig. 3 the curves are actually superimposed so that the two agree closely over a long stretch of the proximal part of their range, the ratio $k / k_{1}$ emerging as 4.0 . But it will be seen that towards their distal ends they diverge sharply, and the two complete curves have a very different appearance. Curve $B$ indicates a life span of almost five times that given by curve $A$. If, on the other hand, they had been superimposed so that their distal ends coincided, giving both an identical range, then the proximal ends would be conspicuously divergent, curve $B$ rising much more sharply than curve $A$.

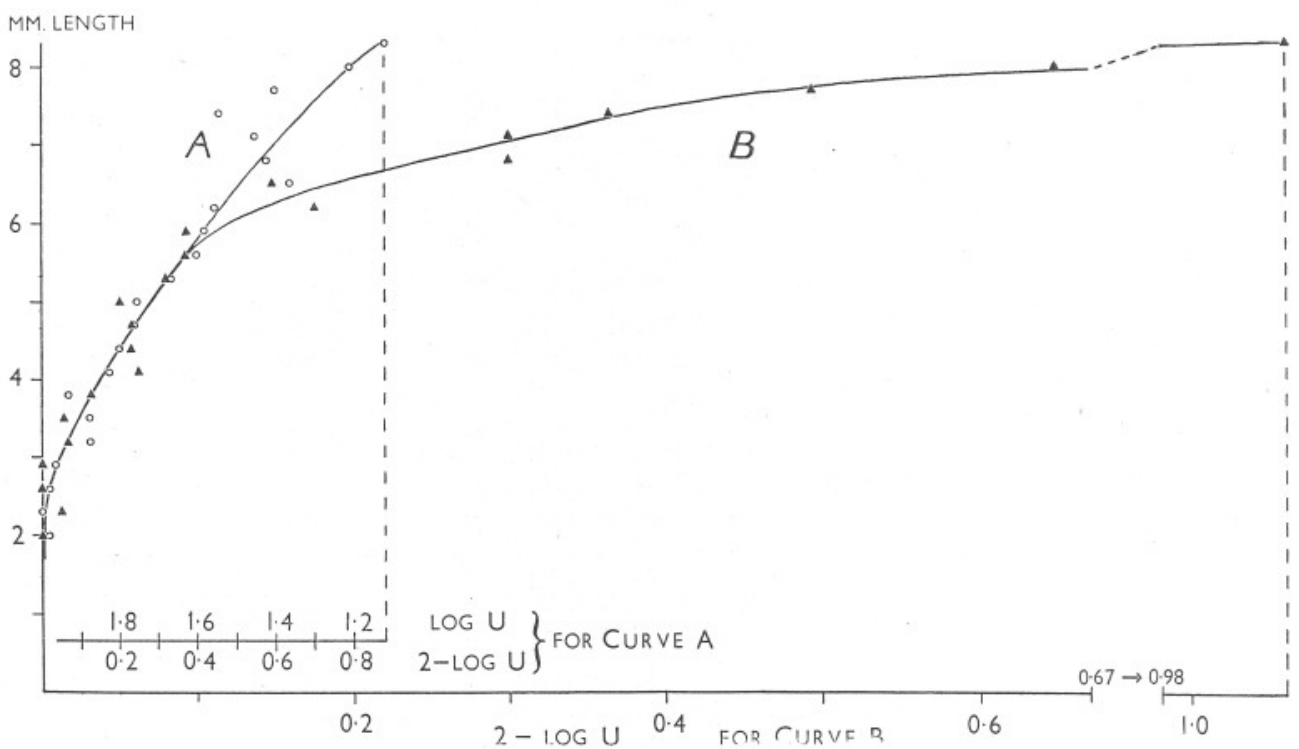

Fig. 3. Theoretical growth-curves of the Littorina deduced from the percentage-infection curves of the two trematodes. $A$, curve from the data of Metacercaria A (small circle plots); $B$, curve from the data of Cercaria B (black triangle plots). $u$, percentage of specimens of snail free from infection. For explanation see text.

The growth curves derived from the data of the two trematode infections are thus grossly dissimilar. Both cannot represent the true growth curve of the snail in the population investigated. One at least of the curves must be false; hence one of the original percentage-infection curves requires some special interpretation. This is the first conclusion reached. It is possible to proceed further and enquire which of the two curves is anomalous.

If it is a question of choosing between curves $A$ and $B$ for the true growth curve of the Littorina, there seems little doubt that $A$ gives a truer picture than $B$. From what is known of growth-rates in molluscs, and from the available evidence for $L$. neritoides itself, there is little hesitation in assessing curve $B$ as extremely improbable. It is, for example, scarcely credible that the snail takes $7 \frac{1}{2}$ times as long to grow from 6 to $8 \frac{1}{2} \mathrm{~mm}$. as it takes to reach 
$6 \mathrm{~mm}$. On the other hand, there is nothing remarkable about curve $A$. Its form is one which might well have been expected, if it is remembered that the habitat involved is peculiarly favourable to growth. It shows quite an appreciable, and more or less steady, decrease in growth-rate with age, a property which would have been more apparent in the graph itself, had not the time scale been abnormally contracted for the sake of securing space for curve $B$. The second conclusion, then, is that it is the curves derived from the data of Cercaria B which are anomalous: there is clearly an undue concentration of snails infected with this cercaria among the larger size-groups.

This conclusion holds whatever may be the cause of the anomaly. One of the few possible causes (see Discussion) is that the parasites affect the growth of infected snails. On this interpretation the present evidence affirms that Cercaria B stimulates growth, rather than that Metacercaria A inhibits it. This is in complete accordance with evidence from other sources.

It should be noted that the above computations are based on the figures for the percentage total infection by each of the two trematodes. In Fig. I another pair of curves is plotted, representing the percentage infection, by each trematode, in that section of the population not infected by the other. It happens that the course of this pair of curves consistently lags behind that of the other pair, since combined infections are appreciably in excess of chance expectations, and single infections correspondingly lower. This second pair of curves becomes increasingly unreliable towards the upper end, as the numbers on which the percentages are based are rapidly reduced in the larger size groups, and this loss of accuracy renders these curves much less satisfactory for the treatment given to the first pair, even if the information they contain is considered more important. However, the results obtained from them, as far as they go, are in entire agreement with those given by the total infection data: in fact an even greater contrast between the two trematodes is indicated.

\section{Discussion}

In earlier papers the author (Rothschild, 1936, 1938) has briefly discussed the accumulation of specimens infected with trematode larvae (parthenitae and cercariae) among the larger snails-an apparently widespread phenomenon. ${ }^{\star}$ This may be due to several causes other than growth stimulation by the parasite:

(I) The young snails may be unattractive to the miracidia and consequently immune to their attack: the infection rate will thus increase with age. off.

(2) Infections may be lethal to young snails which are consequently killed

(3) The growth-rate of the snails may be so greatly slowed down after attaining a certain size, that the time factor alone accounts for the greatly increased percentage of infection in the larger size groups.

* It is of interest to note that in localities where Cercaria B and C were not found in L. neritoides, the largest snails (with one exception) did not exceed $6 \mathrm{~mm}$. in height. 
In considering all these possibilities the paucity of direct evidence in the wild is a serious handicap. For reasons which will be indicated later experimental evidence, particularly of a negative character, can only be accepted with the greatest caution. It is possible that all these factors may play some part in bringing about the accumulation of infected specimens in the largest size groups, even if the author's view is correct and the direct effects on the growth-rate of the host by the parasite, is the principal explanation of the distribution curves shown in Figs. I and 2.

The immunity of immature snails to infection was first postulated by Kemp \& Gravely (I9I9) and Manson-Bahr \& Fairley (1920). It would appear that these authors tended to overlook the fact that the time factor must account for a much smaller number of young snails becoming infected. When the rate of infection is low, giving a total percentage of about I \% as in L. littorea (L.) for example, one must expect to examine several thousand baby snails before encountering a single infection. Up to quite recent times no examination of large numbers of the smallest size groups was carried out, and a general impression was gained that these were immune.

There is quite a large body of experimental evidence which goes to show that miracidia may exert intra- as well as interspecific selection, at any rate in the laboratory. This interesting fact can account for otherwise inexplicable phenomena encountered in the life histories of trematodes and their hosts. Although young snails have sometimes proved immune, in other cases the immunity appears to be conferred on old snails, thus for example: "The older the snail (Segmentina nitidellus Mtd. and Planorbis schmackeri Cless) the less liable it is to infection.... Old snails hold over from the previous season, but these are scarcely ever successfully invaded by miracidia" (Barlow, I925). Again "Old snails (Pomatiopsis lapidaria Say) could not be infected with the miracidia of Paragonimus sp., but an infection of almost $100 \%$ was obtained in young snails of I mm. in length..." (Ameel, I934). Krull (I93I, I934a) also found that full-grown snails (Gyraulus parvus) could not be infected, but snails of one or two days old were susceptible. There is consequently little experimental evidence to support this theory.

Mortality of Young Infected Snails. The same can be said for the second supposition put forward. As a whole there appears to be a remarkable adjustment between host and parasite, and infected snails undoubtedly survive for long periods. In the laboratory Littorina littorea has lived five years (Meyerhof \& Rothschild, 1940) and Peringia ulvae four years, giving off cercariae throughout that period. However, the literature contains many scattered statements which indicate that as a whole, infected snails of all ages are less resistant than uninfected ones (Thomas, I883; Manson-Bahr \& Fairley, 1920; Sewell, 1922; Wesenberg-Lund, 1934; MacHattie, 1936; Porter, 1938; etc.). A sudden change in environment is more apt to kill off parasitized specimens. There is also little doubt that certain species of trematodes such as the Echinostomes (Rankin, 1939; Rothschild, I938) have 
a more lethal effect than others. On the other hand, Mattes (1936) found that Zebrina detrina survived longer when infected than uninfected. It has often been shown that young experimentally infected snails survive to produce cercariae. Krull (I933, I934b), however, found that there was a high mortality of young infected snails and in the case of Fossaria modicella Say infected with Cotylophoron cotylophorum (Fisch.) and Fasciola hepatica L. all died before cercariae producing began. In connexion with the former species he writes: "The snails made little or no growth after having been infected and...it seems reasonable to assume that the amount of food necessary to mature an infection is either not sufficient or does not increase fast enough in a developing snail when infection takes place while the snail is very young."

It must be sufficiently stressed that evidence obtained by laboratory experiments is liable to prove misleading. Again and again failure has resulted from attempts to infect snails with miracidia in artificial surroundings, as apart from other factors, a very slight change in the environment of the snail may render it unsusceptible. Mattes (1936) found it impossible to infect certain snails in his laboratory, but achieved a $100 \%$ infection of the same specimens in his garden. Similarly in the laboratory he successfully infected $100 \%$ of Helicella candidula with Dicrocoelium lanciatum S. \& H., but only $6 \%$ of Zebrina detrina, whereas in nature the infection rates were equal. In the laboratory snails may succumb which under natural conditions would survive. Direct evidence in the wild, both in Peringia ulvae and Littorina neritoides, proves the specimens measuring less than $2 \mathrm{~mm}$. are infected and that these live at any rate until the infections produce cercariae.

Depression of Growth Curve. When considering the third possibility it must be recalled that Sewell (I922) pointed out that Gastropods showed an accelerated growth-rate in the first months of their life. It is also well known that the growth of these molluscs slows down considerably with increasing age. Both Moore (I937) and Lysaght (I94I) have demonstrated this slowing down of growth in L. littorea and L. neritoides in their third and fourth year -a phenomenon much more marked in this genus than in Peringia. However, as shown above, an unusual type of growth curve would have to be postulated for P. ulvae and Littorina neritoides in order to account for the distribution of trematodes throughout the population, supposing infection occurs purely at random.

The Behaviour and Effects of Metacercariae. The facts concerning Metacercaria A recorded by Dr Lysaght agree on the whole with the known observations made on metacercariae which use molluscs as second intermediate host only. Generally such infections appear to occur at random throughout the population, the number of cysts per snail increasing with the time it is exposed to infection. Some examples, however, are reported which clearly indicate selection on the part of the free-swimming cercariae. Thus certain species show a tendency not to re-enter snails infected with their own sporocysts, though readily entering 
those infected with other species (Winfield, I933; Nolf \& Cort, I933). In Metacercaria A it would appear that the free-swimming cercaria is attracted by snails already infected with Cercaria B. A more probable explanation of the high number of these combined* infections is that the sluggish behaviour of infected snails gives the cercariae a better chance to penetrate.

Apart from possible mechanical obstruction caused by the presence of large numbers of cysts, snails appear to be little if at all affected by the presence of metacercariae $\nmid$ using them as second intermediate host only. There is no active destruction of the tissues and sterility does not result. Dr Lysaght draws attention to this fact for Metacercaria A. It is the fact that metacercariae apparently cause no serious histopathological changes in the host, which makes them a suitable subject for comparison with primary infections.

Although no further conclusions can be reached with regard to the actual cause $\ddagger$ of the large size of snails serving as first intermediate host for trematodes, such a comparison tends to heighten the belief that these parasites induce growth.

\section{SUMMARY}

If the number of infections with (a) trematode parthenitae and cercariae using Littorina neritoides as first intermediate host only, and $(b)$ encysted metacercariae using L. neritoides as second intermediate host only, are plotted against the size of the snails, two different curves result. The first shows a low rate of infection in the small size groups, but a steep upward slope rising to $9 \mathrm{I} \%$ in the large size groups. The second shows a curve increasing uniformly to $87 \%$ infection.

Possible interpretations are discussed, and it is concluded that the difference is probably due to the fact that primary infections cause accelerated growth in the host.

* The term "double infection" is reserved for infestations with two primary infections, i.e. two species of cercariae each using a mollusc as first intermediate host. The term "combined infection" is proposed for infections consisting of parthenitae of one species using the snail as first intermediate host and metacercariae of another species using it as second intermediate host.

$\dagger$ This term does not include Tetracotyle which are known to be detrimental to the snail (Van Haitsma, I930).

$\neq$ The suggestion was originally put forward that castration might account for the increase in size of infected snails. Littorina littorea, artificially castrated by treatment with X-rays in doses of $400 \mathrm{r}$. at $150 \mathrm{kV}$. and $4 \mathrm{~mA}$., screened with $4 \mathrm{~mm}$. Al., did not grow any faster or any larger than controls. 


\section{REFERENCES}

Ameel, D. J., I934. Paragonimus, its life history and distribution in North America and its taxonomy (Trematoda: Troglotrematidae). Amer. Fourn. Hyg., Vol. xIx, pp. 279-3I7, 7 pls.

BARLOW, C. H., I925. The life cycle of the human intestinal fluke Fasciolopsis buski (Lankester). Amer. Fourn. Hyg., Monogr. Ser., No. 4, pp. I-98, Io pls., I2 figs.

Kemp, S. \& Gravely, F. H., I9I9. On the possible spread of Schistosomiasis in India. Indian fourn. Med. Res., Vol. vII, pp. $25 \mathrm{I}-64$.

KRULL, W. H., I93I. Life history studies on two frog lung flukes, Pneumonoeces medioplexus and Pneumobites parviplexus. Trans. Amer. Micr. Trans., Vol. L, pp. $215-77,2$ pls.

I933. New snail and rabbit hosts for Fasciola hepatica Linn. Fourn. Parasit. Urbana, Vol. xx, pp. 49-52.

- I934 $\mathrm{a}$. Some additional notes on the life history of a frog lung fluke, Haematoloechus complexus (Seely, I906) Krull. Trans. Micr. Soc., Vol. LIII, pp. I96-9.

- I934b. Life history studies on Cotylophoron cotylophorum (Fischoeder, I90I) Stiles and Goldberger, I910. Fourn. Parasit. Urbana, Vol. xx, pp. I73-80, I fig.

LYSAGHT, A., I94I. The biology and trematode parasites of the gastropod Littorina neritoides (L.) on the Plymouth Breakwater. Fourn. Mar. Biol. Assoc., Vol. xxv, pp. 4I-67, II figs.

MacHattie, C., I936. The relation between Schistosomiasis (Bilharziasis) in domestic animals and man as observed in Iraq. Inst. Veter. Pathol. Univ. Zürich, pp. I-75, I7 pls.

MANSON-BAhr, P. \& FaIRley, H. N., 1920. Observations on Bilharziasis amongst the Egyptian Expeditionary Force. Parasitol. Cambridge, Vol. xII, pp. 33-7I, 3 figs.

Mattes, O., 1936. Der Entwicklungsgang des Lanzettegels Dicrocoelium lanceatum. Z. Parasitk. Berlin, Vol. vin, pp. 37I-430, I5 figs.

MeYerhof, E. \& Rothschild, M., I940. A prolific trematode. Nature, London, Vol. CXLVI, p. 367.

Moore, H. B., I937. The biology of Littorina littorea. Part I. Growth of the shell and tissues, spawning, length of life and mortality. Fourn. Mar. Biol. Assoc., Vol. XXI, pp. $72 \mathrm{I}-42,3$ pls., Io figs.

Nolf, L. O. \& CORT, W. W., I933. On immunity reactions of snails to the penetration of the cercariae of the Strigeid trematode, Cotylurus flabelliformis (Faust). Fourn. Parasit. Urbana, Vol. xx, pp. 38-48.

Porter, A., I938. The larval Trematoda found in certain South African Mollusca with special reference to Schistosomiasis (Bilharziasis). S. African Inst. Med. Res., Vol. vIII, No. 42, pp. I-492, 83 pls., I fig.

RANKIN, J. S., 1939. Ecological studies on larval trematodes from Western Massachusetts. Fourn. Parasit. Urbana, Vol. xxv, pp. 309-28, 2 pls.

Rothschild, M., 1936. Gigantism and variation in Peringia ulvae (Pennant) I777, caused by infection with larval trematodes. Fourn. Mar. Biol. Assoc., Vol. xx, pp. 537-46, 2 figs.

- 1938. Further observations on the effect of trematode parasites on Peringia ulvae (Pennant) I777. Novit. Zool., Tring, Vol. XLI, pp. 84-102, 2 pls., 7 figs.

Rothschild, A. \& Rothschild, M., I939. Some observations on the growth of Peringia ulvae (Pennant) 1777 in the laboratory. Novit. Zool., Tring, Vol. XLI, pp. 240-7, 3 figs.

Sewell, R. S., I922. Cercariae indicae. Ind. Fourn. Med. Res. Calcutta, Vol. x (suppl. no.), pp. I-370, 7 pls. 
Thomas, A. P., I883. The life-history of the liver fluke (Fasciola hepatica). Quart. Fourn. micr. Sci., Vol. xxIII, pp. 99-133, 2 pls.

Van Haitsma, J. P., I930 (I93I). Studies on the trematode family Strigeidae (Holostomidae). No. XXII: Cotylurus flabelliformis (Faust) and its life-history. Pap. Mich. Acad. Sci., Vol. xIII, pp. 337-482, 2 pls.

WESENBERG-LUND, C., I934. Contributions to the development of the Trematoda Digenea. Part II. The biology of the freshwater cercariae in Danish freshwaters. K. danske Vidensk. Selsk. Skr., Vol. v, pp. I-223, 39 pls.

WINFIELD, G. F., I933. On the immunity of snails infested with the sporocysts of the Strigeid, Cotylurus flabelliformis, to the penetration of its cercaria. Fourn. Parasit. Urbana, Vol. xIx, pp. 130-3. 